\title{
A Retrospective Study of Endoscopic Findings in Patients Presenting with Dyspepsia in a Rural Teaching Hospital
}

\author{
Gurung $D^{1}$, Khati $S^{2}$ \\ Corresponding Author: \\ Dr. Dhiraj Gurung \\ Karnali Academy of Health Sciences, Jumla, Nepal \\ Email: dhirajinternalmedicine@gmail.com
}

${ }^{1}$ Department of Internal Medicine, Karnali Academy of Health Sciences, Jumla, Nepal, ${ }^{2}$ Department of General Practice and Emergency Medicine, Karnali Academy of Health Sciences, Jumla, Nepal.

\begin{abstract}
Introduction: Dyspepsia is a common problem faced in our country and elsewhere. Benign causes predominate with occasional incidences of carcinoma of the stomach, esophagus. The presence of warning signs helps indicate the presence of such carcinomas though various studies differ as to its usefulness.

Methods: Patients presenting with dyspepsia were investigated with a gastroscope to see the etiological pattern seen in the Karnali region and the usefulness of the warning signs. This study included the initial 100 patients undergoing upper gastrointestinal endoscopy for dyspepsia evaluation in our institution.

Results: The majority of the patients (53\%) showed normal findings on visual examination despite being symptomatic suggestive of functional dyspepsia. The most common warning sign was weight loss which had a positive predictive value of only $4 \%$. Malena was present in $10 \%$ of the patients with a positive predictive value of $30 \%$

Conclusions: Significant weight loss as a warning sign to screen patients for gastrointestinal pathology seems unsuitable in the rural setting.
\end{abstract}

Keywords: dyspepsia, gastroscope, karnali, warning sign

\section{INTRODUCTION}

Dyspepsia can be simply put as episodic or persistent symptoms that include abdominal pain or discomfort and which are referable to the upper gastrointestinal tract. ${ }^{1}$ It forms a large portion of the medical OPD visits in our institution. Studies show similar proportion of OPD visits in other institutions. ${ }^{2}$

Once the decision has been made to investigate, the diagnostic test of choice is endoscopy. ${ }^{3}$ Patients with new onset dyspepsia after 45 to 55 years of age and those with features that suggest structural disease are advised to undergo initial endoscopy. ${ }^{4-7}$ In a meta-analysis of 15 studies evaluating more than 57,000 patients with dyspepsia, alarm symptoms showed a positive predictive value for GI cancer of less than $11 \%$ in all but 1 of these studies. ${ }^{8}$ The negative predictive value of an absence of alarm symptoms was much better at more than $97 \%$ due to the low prevalence of GI cancer. One-fourth of patients with malignancy and dyspepsia do not report alarm symptoms. ${ }^{9}$

Directed questioning for the presence of alarm symptoms (e.g., unexplained weight loss, recurrent vomiting, progressive dysphagia, odynophagia, gastrointestinal blood loss and family history of upper gastrointestinal cancer) is important; however, the presence of alarm symptoms may indicate advanced disease and thus limited treatment options. ${ }^{10,11}$ Though cancer of the UGI tract is usually advanced at the time of diagnosis, a low threshold of suspicion for gastric malignancy may result in earlier diagnosis and improved survival. However cancer accounts for only 1-2\% of diagnoses at UGI tract and less in patients under the age of 50 years. ${ }^{12}$ 
More than half of these patients presenting with dyspepsia have no detectable cause for their symptoms and only $20 \%$ of patients have significant gastroduodenal lesions, such as peptic ulcer. ${ }^{13-18}$ Patients in whom investigations have revealed no organic cause are classified as having functional dyspepsia. ${ }^{19}$

\section{METHODS}

This was a retrospective study carried out at Karnali Academy of Health Sciences to include the initial 100 patients presenting with dyspepsia undergoing diagnostic upper gastrointestinal endoscopy. Data was collected to include name, age, and sex, date of procedure, dyspepsia duration, warning signs, and endoscopic findings Dyspepsia will be defined here as episodic or persistent abdominal pain or discomfort which is referable to the upper gastrointestinal tract. Significant weight loss has been defined here as loss of greater than $10 \%$ body weight over a period of 6 months or history of previously fitting clothes becoming loose. Inclusion criteria are cases who underwent upper gastrointestinal tract endoscopy for dyspepsia evaluation.

\section{Limitations of the study}

Due to the unavailability of histopathological evaluation biopsy will not be taken in all cases. The lack of biopsy sampling in all patients can lead to us missing histologic gastritis as well as Helicobacter pylori infection.

\section{RESULTS}

A total of 100 patients underwent upper gastrointestinal endoscopy for evaluation of dyspepsia in a period of 4 months.

Table 1. Warning features

Significant weight loss-

$25 / 100$

Malena-

$10 / 100$

Hematemesis-

$2 / 100$

Anemia-

$1 / 100$

Abdominal mass-

$0 / 50$

Dysphagia-

$4 / 100$

Absent warning features-

$8 / 100$

Significant weight loss is the most common warning feature seen amongst our patient group. Endoscopy for dyspepsia evaluation despite absence of warning features also forms a significant proportion of the patients.

Table 2. Endoscopic findings

Normal

Antral gastritis

$11 / 100$

Fundal gastritis

$2 / 100$

Duodenitis

$10 / 100$

Gastric ulcer

$4 / 100$

Duodenal ulcer

$4 / 100$

Mallory Weiss tear

$3 / 100$

Pangastritis

$10 / 100$

Varies

$1 / 100$

Hiatus

$3 / 100$

Esophageal pathology

$4 / 100$

Normal findings seem to be present in the majority of our patients. Esophageal mass was seen in one of our patients. There were 2 cases of esophagitis and 1 case of esophageal ulcer.
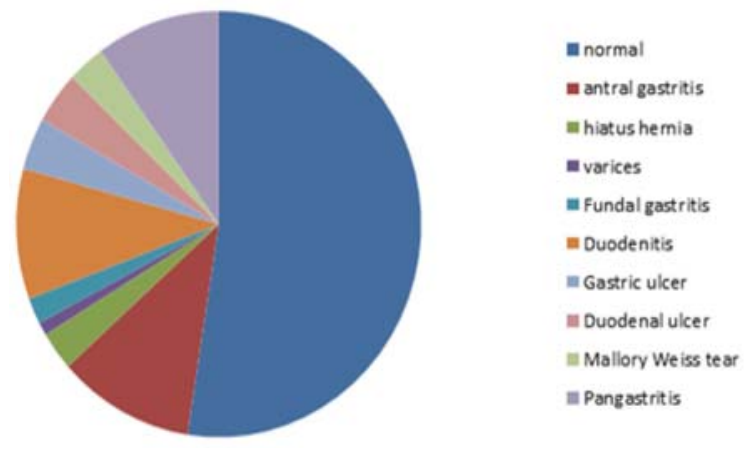

Pie chart showing findings present in the majority of our patient group.

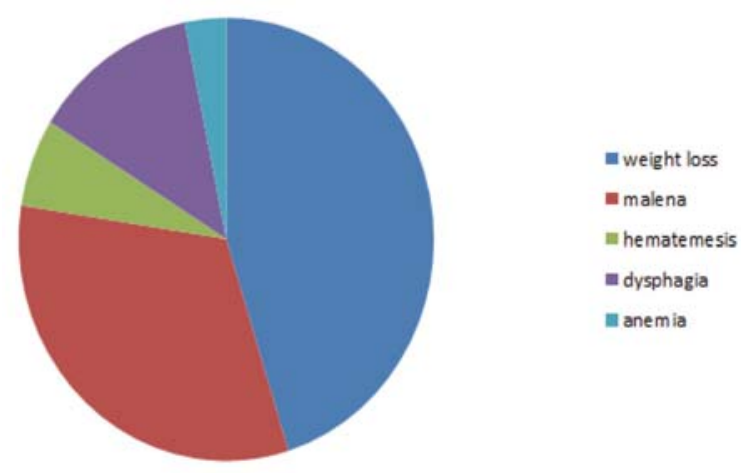

Pie chart showing the proportion of warning features-

Correlation of warning sign with positive findings- 
Significant weight loss- total 25 of which 24 normal, 1 multiple ulcers in body and antrum Forrest grade III

Malena- total 10 of which 7 normal, 1 duodenitis, 1 multiple duodenal ulcer, 1 gastric ulcer

Hematemesis- total 2 with both Mallory Weiss tear

Anemia- total 1-Normal

Dysphagia- total 4 with 1 esophageal mass, 1 esophageal ulcer, 2 Esophagitis

Table 3. Positive and negative predictive value for significant weight loss for GIT pathology-

\begin{tabular}{|l|l|l|l|}
\hline & $\begin{array}{l}\text { Disease } \\
\text { present }\end{array}$ & $\begin{array}{l}\text { Disease } \\
\text { absent }\end{array}$ & Total \\
\hline Wt loss present & 1 & 24 & 25 \\
\hline Wt loss absent & 46 & 29 & 75 \\
\hline Total & 47 & 53 & \\
\hline
\end{tabular}

Hence, positive predictive value- $1 / 25=0.04$ or $4 \%$, negative predictive value- $29 / 75=0.38$ or $38 \%$, sensitivity $1 / 1+29=0.033$ or $3 \%$, specificity$29 / 24+29=0.54$ or $54 \%$

Table 4. Positive and negative predictive value for malena for GIT pathology-

\begin{tabular}{|l|l|l|l|}
\hline & $\begin{array}{l}\text { Disease } \\
\text { present }\end{array}$ & $\begin{array}{l}\text { Disease } \\
\text { absent }\end{array}$ & Total \\
\hline Malena present & 3 & 7 & 10 \\
\hline Malena absent & 44 & 46 & 90 \\
\hline Total & 47 & 53 & \\
\hline
\end{tabular}

Hence, positive predictive value- $3 / 10=0.3$ or $30 \%$, negative predictive value- $46 / 92=0.5$ or $50 \%$, sensitivity- $3 / 3+46=0.061$ or $6 \%$, specificity$46 / 46+7=0.86$ or $86 \%$

\section{DISCUSSION}

Endoscopic evaluation of dyspepsia without warning features seem to form a significant proportion of the patients evaluated. The persistence and/or recurrence of dyspepsia despite prior proton pump inhibitor therapy seems to play a major role in patients insisting on this procedure. Some of the patients who have undergone the endoscopic evaluation despite absent warning features were those with prior history of antral gastritis and duodenal ulcers.
Normal endoscopic finding seems to be the most common finding amongst patients undergoing endoscopy which is consistent with findings as seen in other studies. ${ }^{20,21,22}$ The percentage of normal finding on endoscopy in our study is however much higher. Possible factor could be the higher proportion of patients presenting with absent warning features. The introduction of endoscopic services in this region has resulted in a large number of patients of probable anxiety disorder insisting on the procedure with some mimicking the warning features.

Significant weight loss is the most common warning feature. Only one case amongst the 25 weight loss patients showed a pathology showing a very low positive predictive value. It was a case of gastric ulcer whose biopsy did not show carcinoma. Significant weight loss could be a result of the higher incidence of helminthic infestation and other infective etiologies of chronic diarrhea like giardiasis amongst this population.

Amongst the warning signs, dysphagia and hematemesis seems to be the most reliable indicator of a gastrointestinal pathology. Malena was present in 10 patients with only 3 of our patients showing some upper git pathology showing a positive predictive value of $50 \%$. We were unable to evaluate below the level of the second part of the duodenum due to unavailability of double balloon enteroscope. Amongst the biopsy taken only 2 returned with their histopathological examination. The rest were lost to follow up so we were unable to determine if carcinoma was present.

\section{CONCLUSIONS}

Weight loss should be excluded as one of the warning feature or at the very least, not be taken alone as a criteria for screening gastroscopy.

\section{Conflict of Interest: None}




\section{REFERENCES}

1. Heading RC. Definitions of dyspepsia. Scand J Gastroenterol Suppl 1991; 182: 1-6

2. Khan N, Shabbir G, Zarif $M$, et al. Upper gastrointestinal endoscopic assessment of patients presenting with dyspepsia. JPMI 2007; 21:209-16

3. Akhtar A, Shaheen M. Dyspepsia in African American and hispanic patients. J Natl Med Assoc 2004; 96: 635-40

4. Talley NJ. American Gastroenterological Association medical position statement: evaluation of dyspepsia. Gastroenterology 2005; 129: 1753-5

5. Talley NJ, Vakil N. Guidelines for the management of dyspepsia. Am J Gastroenterol 2005; 100: 2324-37

6. Lieberman D, Fennerty M.B, Morris C.D, et. al. Endoscopic evaluation of patients with dyspepsia: results from the national endoscopic data repository. Gastroenterology 2004; 127: 1067-75

7. Malfertheiner P. Commentary: how, in whom, and when to diagnose Helicobacter pylori. Gastroenterology 1997; 113(6): 118-9

8. Vakil N, Moayyedi P, Fennerty MB, et al. Limited value of alarm features in the diagnosis of upper gastrointestinal malignancy: systematic review and meta-analysis. Gastroenterology 2006; 131: 390-401

9. Fransen GA, Janssen MJ, Muris JW, et al. Metaanalysis: the diagnostic value of alarm symptoms for upper gastrointestinal malignancy. Aliment Pharmacol Ther 2004; 20: 1045-52

10. Bowrey D.J, Griffin S.M, Wayman J, et al. Use of alarm symptoms to select dyspeptics for endoscopy causes patients with curable esophagogastric cancer to be overlooked. Surg Endosc 2006; 20: $1725-8$

11. Blackshaw G.R, Barry J.D, Edwards P, et al. Openaccess gastroscopy is associated with improved outcomes in gastric cancer. Eur J Gastroenterol Hepatol 2003; 15: 1333-7
12. Bolling-Sternevald E, Carlsson R, Aalykke C, et al. Self-administered symptom questionnaires in patients with dyspepsia and their yield in discriminating between endoscopic diagnoses. Dig Dis 2002; 20: 191-8

13. Valle PC, Breckan RK, Amin A. "Test, score and scope": a selection strategy for safe reduction of upper gastrointestinal endoscopies in young dyspeptic patients referred from primary care. Scand J Gastroenterol 2006; 41: 161-9

14. Spiller RC. Anorexia, nausea, vomiting and pain. $\mathrm{Br}$ Med J 2001; 323: 1354-7

15. Fisher RS, Parkman HP. Management of nonulcer dyspepsia. NEJM 1998; 339: 1376-81

16. Talley NJ,Silverstein MD,Agreus L,etal.AGAtechnical review: evaluation of dyspepsia. Gastroenterology 1998; 114: 582-95

17. Richter JE. Dyspepsia: organic causes and differential characteristics from functional dyspepsia. Scand J Gastroenterol. 1991; 182: 11-6

18. Thompson WG. Nonulcer dyspepsia. Can Med Assoc J. 1984; 130: 565-9

19. Locke GR. Nonulcer dyspepsia: what it is and what it is not. Mayo Clin Proc 1999; 74: 10115

20. Fisher JA, Surridge JG, Var tan CP, et al. Upper gastrointestinal endoscopy: a GP service. BMJ 1977; 2: 1199-201

21. Beavis AK, La Brooy S, Misiewicz JJ. Evaluation of one-visit endoscopic clinic for patients with dyspepsia. BMJ 1979; 1: 1387-9

22. Holdstock G, Wiseman M, Loehry CA. Openaccess endoscopy service for general practitioners. BMJ 1979; 1: 457-9 